\title{
Girassol suplementado com percolado de aterro sanitário e submetido à salinidade
}

\section{Sunflower supplemented with landfill percolate and submitted to salinity}

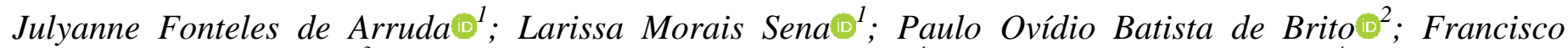 \\ Holanda Nunes Júnior $\oplus^{3}$; Roberto Albuquerque Pontes Filho $\oplus^{4}$; Franklin Aragão Gondim $\oplus^{4}$
}

${ }^{1}$ Graduandas em Engenharia Ambiental e Sanitária, Instituto Federal de Educação Ciência e Tecnologia do Ceará, Maracanaú, Ceará, julyannefarruda@yahoo.com.br; larissasenaoi54@gmail.com; ${ }^{2}$ Mestrando do Programa de Pós-Graduação em Energias Renováveis, Instituto Federal de Educação Ciência e Tecnologia do Ceará, Maracanaú, Ceará, paulobatistaengenharia@ gmail.com, ${ }^{3}$ Professor do Instituto Federal de Educação Ciência e Tecnologia do Ceará,

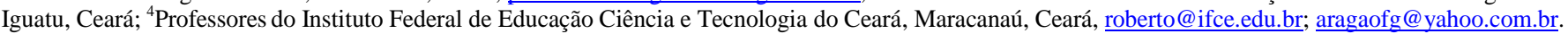

\section{A R T I G O}

Recebido: $19 / 08 / 2019$

Aprovado: 20/09/2019

Palavras-chave:

Concentração Salina

Helianthus annuus L.

Fertilização

Análises

Crescimento

\section{Key words:}

Saline concentration

Fertilization

Helianthus annuus L.

Growth Analyzes

\section{R E S U M O}

O percolado de aterro sanitário é um líquido produzido a partir de processos físicos, químicos e biológicos aos quais os resíduos sólidos urbanos são submetidos nos aterros sanitários. Apresenta uma composição físico-química variável e pode conter altos teores de nutrientes, sendo assim empregado na fertilização de plantas. Por isso, objetivou-se avaliar o crescimento de plantas de girassol irrigadas com água de moderada salinidade e com suplementação nutricional com percolado de aterro sanitário. $\mathrm{O}$ experimento foi conduzido em área experimental com cobertura de nylon (sombrite), sob delineamento inteiramente casualizado em um fatorial 4 x 2, sendo [1: 100\% de areia de granulometria fina - NBR 6502; 2: areia + adubo/fertilizante orgânico misto (mistura de bagaço de cana, esterco bovino, esterco de galinha, serragem de madeira e gesso agrícola) e $80 \mathrm{~kg} \mathrm{de} \mathrm{N} \mathrm{ha}^{-1}, 3$ : areia + percolado de aterro sanitário e $80 \mathrm{~kg} \mathrm{de} \mathrm{N} \mathrm{ha}^{-1}$; e 4: areia + percolado de aterro sanitário e 160 $\mathrm{kg}$ de $\mathrm{N} \mathrm{ha}^{-1}$ ] e duas concentrações salinas da água de irrigação [irrigação com água destilada ou solução de $\mathrm{NaCl}$ a $60 \mathrm{mM}$ ], com 10 repetições, em vasos de 12 L. Foram realizadas análises de crescimento (altura, diâmetro do coleto, número de folhas), teores relativos de clorofila e diâmetro dos capítulos. Nas condições experimentais empregadas, substrato arenoso, as concentrações de percolado de aterro sanitário utilizadas promoveram incrementos em todas as variáveis de crescimento analisadas nas plântulas de girassol, especialmente a $80 \mathrm{Kg} \mathrm{N}^{-1}$. A irrigação com solução de $\mathrm{NaCl}$ a $60 \mathrm{mM}$ não ocasionou efeitos negativos nas variáveis de crescimento, demonstrando assim a tolerância moderada das plantas de girassol à salinidade em substrato arenoso.

\section{A B S T R A C T}

Landfill percolate is a liquid produced from physical, chemical and biological processes to which municipal solid waste is subjected to landfills. It has a variable physicochemical composition and may contain high levels of nutrients, thus being used in plant fertilization. Therefore, the aim of this work was to evaluate the growth of sunflower plants irrigated with water of moderate salinity and with nutritional supplementation with landfill percolate. The experiment was carried out in experimental area under a completely randomized design in a 4 x 2 factorial design (1: 100\% fine grained sand - NBR 6502; 2: sand + mixed organic fertilizer (sugarcane bagasse mix, cattle manure, chicken manure, wood sawdust and agricultural plaster) and fertilizer $80 \mathrm{~kg} \mathrm{~N} \mathrm{ha}^{-1}$, 3: sand + landfill percolate $80 \mathrm{~kg} \mathrm{~N} \mathrm{ha}^{-1}$, and 4: sand + landfill percolate $160 \mathrm{~kg} \mathrm{~N} \mathrm{ha}^{-1}$ ) and two saline concentrations of irrigation (distilled water or $60 \mathrm{mM} \mathrm{NaCl}$ solution), with 10 repetitions in $12 \mathrm{~L}$ pots. Growth analyzes (height, stem diameter, leaf number), relative chlorophyll content and chapter diameter were performed. Under the experimental conditions employed, sandy substrate, landfill percolate concentrations used promoted increases in all growth variables analyzed in sunflower seedlings, especially at $80 \mathrm{Kg} \mathrm{N} \mathrm{ha}{ }^{-1}$. Irrigation with $60 \mathrm{mM} \mathrm{NaCl}$ solution did not cause negative effects on growth variables, thus demonstrating the moderate tolerance of sunflower plants to salinity in sandy substrate.

\author{
Revista Verde \\ ISSN 1981-8203 \\ Pombal, Paraíba, Brasil
}

v. 14, n.4, out.-dez, p.524-530, 2019

doi: $10.18378 /$ rvads.v14i4.6735 


\section{INTRODUÇÃO}

O girassol (Helianthus annuиs L.) é uma dicotiledônea anual da família Asteraceae com grande potencial agrícola, podendo ser largamente utilizada como alternativa agrícola no semiárido brasileiro (SILVA et al., 2017). A cultura está aclimatada às condições edafoclimáticas da região e apresenta curto ciclo de vida (SILVA et al., 2016).

A sua produção é destinada para a produção melífera, ornamental, forragem alternativa, óleo para alimentação humana e, principalmente, a produção de biocombustíveis, sendo uma das melhores alternativas vegetais (SANTOS JÚNIOR et al., 2011). A cultura é moderadamente tolerante à salinidade, contudo, é possível observar efeitos deletérios, tais como alterações no metabolismo, na anatomia, na morfologia e no crescimento das plantas (DA SILVA et al., 2015).

As regiões áridas e semiáridas são conhecidas por apresentarem precipitações concentradas em curto período ao longo do ano, além de elevada evapotranspiração, contribuindo para o acúmulo de sais nos solos. Essas intempéries dificultam a agricultura, devido à maioria das culturas agrícolas serem intolerantes ao excesso de sais no solo (SILVA et al., 2017). Outro problema encontrado pelos agricultores é o tipo de água disponível nessas regiões, a qual muitas vezes também possui alto teor salino (RIBEIRO et al., 2016). A salinidade é um dos fatores que mais atinge a produção e a qualidade das espécies agrícolas, podendo inibir o crescimento das plantas e até causar a morte.

Além da salinidade dos solos, outra condição existente nessas regiões são os solos com baixa fertilidade natural. Isso se constitui em um fator limitante da produtividade das culturas devido à carência de nutrientes essenciais ao seu crescimento e desenvolvimento (SOARES et al., 2015).

O percolado de aterro sanitário é uma substância líquida produzida a partir de processos físicos, químicos e biológicos aos quais os resíduos sólidos urbanos são submetidos nos aterros. Esse líquido apresenta uma composição físico-química variável e pode conter altos teores de nutrientes presentes neste biocomposto. Entre esses componentes, é possível encontrar o nitrogênio, macronutriente importante no cultivo de plantas, tornando assim a utilização possível e uma solução ambientalmente correta para a disposição final desse produto (NUNES JÚNIOR et al., 2016).

$\mathrm{Na}$ literatura atual, não há relatos sobre os efeitos da suplementação com percolado de aterro sanitário no crescimento de plantas de girassol crescendo sob condições de salinidade. Dada a importância econômica do girassol, a existência de áreas que enfrentam problemas de salinidade na região e a necessidade de uma destinação adequada do percolado gerado em aterros sanitários, os estudos contextualizados nas condições de salinidade mostram-se relevantes. Portanto, a hipótese do trabalho é que o percolado de aterro sanitário ocasiona melhoria no crescimento desta cultura, mesmo irrigado com moderada concentração salina $(60 \mathrm{mM}$ de $\mathrm{NaCl})$.

Diante do exposto, o presente trabalho teve como objetivo avaliar a utilização do percolado de aterro sanitário sobre o crescimento de plantas de girassol irrigadas com água com moderada concentração salina, estudando-se os efeitos em variáveis vegetativas e reprodutivas.

\section{MATERIAL E MÉTODOS}

O experimento foi conduzido em área experimental localizada no Instituto Federal de Ciência e Tecnologia do Ceará campus Maracanaú, Ceará, Brasil, cidade que possui um clima Tropical quente subúmido, durante os meses de janeiro a abril de 2018. A área experimental utilizada possui uma cobertura com tela de plástico do tipo nylon, possibilitando um sombreamento de $50 \%$. No entanto, as precipitações pluviométricas caem no ambiente de cultivo das plantas.

$\mathrm{O}$ experimento foi disposto em delineamento inteiramente casualizado (DIC), em esquema fatorial $4 \times 2$, sendo quatro fertilizações dos substratos (1: 100\% em volume de areia de granulometria fina - NBR 6502 peneirada em malha de $5 \mathrm{~mm}$ e lavada com água destilada; 2: areia + adubo/fertilizante orgânico misto com $80 \mathrm{~kg}$ de $\mathrm{N} \mathrm{ha}^{-1}$, 3: areia + percolado de aterro sanitário a $80 \mathrm{~kg} \mathrm{de} \mathrm{N} \mathrm{ha}^{-1}$; e 4 : areia + percolado de aterro sanitário a $160 \mathrm{~kg}$ de $\mathrm{N} \mathrm{ha}^{-1}$ ) e dois níveis de salinidade da água de irrigação (irrigação com água destilada ou solução de $\mathrm{NaCl}$ a $60 \mathrm{mM}$ ), com 10 repetições e espaçamento de $50 \mathrm{~cm}$ entre os vasos. Em vasos de $12 \mathrm{~L}$ (medidas aproximadas: $25 \mathrm{~cm}$ de altura e $30 \mathrm{~cm}$ de diâmetro) contendo 5 perfurações no fundo com $1 \mathrm{~cm}$ de diâmetro para a drenagem da água excedente, foram semeadas 5 sementes. Aos 7 dias após a semeadura (DAS) foi realizado um desbaste, deixando-se apenas duas plantas por vaso. A irrigação foi realizada a $80 \%$ da capacidade de campo. A reposição de água aconteceu diariamente levandose em consideração a água evapotranspirada por meio de pesagem dos vasos.

O fertilizante orgânico misto utilizado foi de origem comercial, tendo em sua composição esterco bovino e de galinha, serragem de madeira, bagaço de cana e gesso agrícola e concentração de N-t de $120 \mathrm{~g} . \mathrm{kg}^{-1}$. O percolado de aterro sanitário possuía em sua composição em mg. $\mathrm{L}^{-1}$ : N-t 364; P-t 7,$9 ; \mathrm{Fe}^{+2} 16,1 ; \mathrm{Zn} 22,3 ; \mathrm{Mn} 24,5 ; \mathrm{Cu} 1,5 ; \mathrm{P}_{2} \mathrm{O}_{5} 18,1 ; \mathrm{K}_{2} \mathrm{O} 2,19$; $\mathrm{K}^{+} 1,8 ; \mathrm{Na}^{+} 235 ; \mathrm{Ca}^{2+} 54 ; \mathrm{Mg}^{2+} 58,5 ; \mathrm{Cl}^{-} 96$.

Para ambos, fertilizante orgânico misto e percolado de aterro sanitário, as quantidades adicionadas aos vasos foram calculadas de acordo com as concentrações de N-t. Foram realizados cálculos para a extrapolação das condições de campo (adição em $\mathrm{kg}$ de $\mathrm{N} \mathrm{ha}^{-1}$ ) para vasos individuais. O percolado foi acrescido nas 4 semanas iniciais, 1 vez por semana até alcançar as concentrações finais desejadas $(80$ e $160 \mathrm{~kg}$ de $\mathrm{N}$ ha $\left.{ }^{1}\right)$. O fertilizante orgânico misto foi acrescido uma única vez no início do experimento. Durante o período experimental não houve a necessidade da aplicação de novos nutrientes aos vasos, bem como não foram aplicados defensivos agrícolas.

As avaliações de crescimento foram realizadas durante todo o ciclo da cultura, aos 14, 29, 36, 42 e 62 DAS. Para altura, foram medidas as plantas desde o solo até a gema apical com uma régua graduada em centímetros. Ao mensurar o diâmetro do coleto, foi utilizado um de paquímetro digital $150 \mathrm{~mm}$ - Aço Inox Lee Tools Mod. 684132.

As sementes de girassol (H. annus), cultivar BRS 323 foram fornecidas pela Embrapa Produtos e Mercado, escritório 
Dourados-MS. O percolado de aterro sanitário foi coletado no Aterro Metropolitano Oeste de Caucaia - ASMOC nos dias 09 de novembro de 2017 e 17 de janeiro de 2018.

Os teores relativos de clorofila (índices SPAD) foram obtidos com um medidor portátil específico (modelo Minolta SPAD - 502, Osaka, Japão), na primeira folha completamente expandida, e o número de folhas por contagem direta daquelas que estivessem completamente expandidas.

Logo que as inflorescências (capítulos) se abriram (aproximadamente aos 50 dias), em seu estádio R5 (GAZZOLA et. al., 2012), realizou-se a cada 3 dias a polinização de forma mecânica com o auxílio de um pincel. Avaliaram-se também os diâmetros dos capítulos no momento de maturação fisiológica (em média aos 55 dias) com a utilização de uma régua graduada em $\mathrm{cm}$. $\mathrm{O}$ experimento foi conduzido durante a quadra chuvosa do município de Maracanaú-CE (Figura 1).

Figura 1. Precipitações médias no município de Maracanaú-CE nos meses janeiro a abril de 2018 (FUNCEME, 2018).

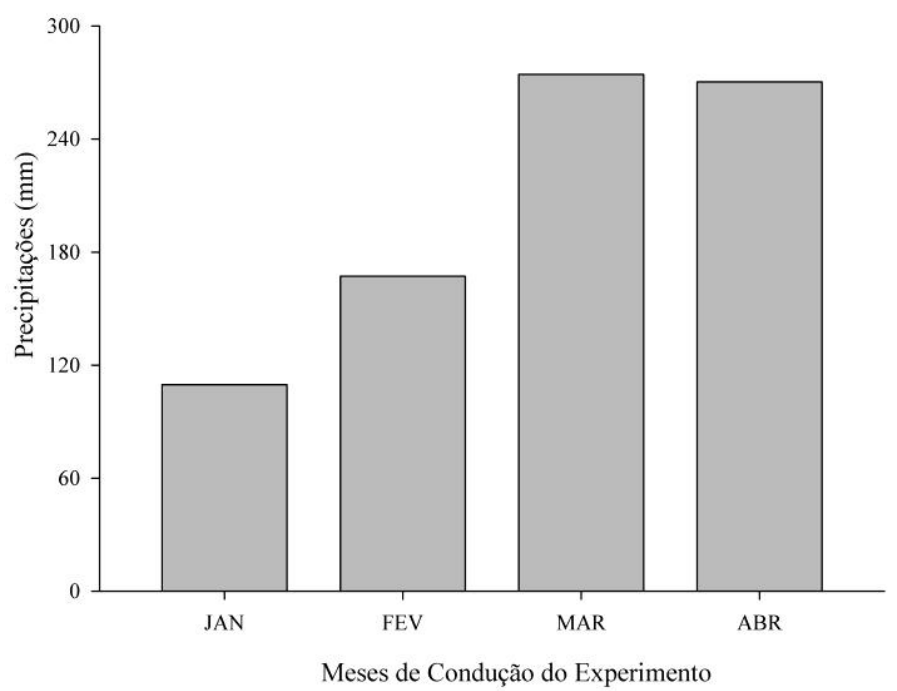

Ao final do período experimental, retiraram-se amostras dos substratos para determinação do $\mathrm{pH}$ e condutividade elétrica. Após secagem, os substratos foram misturados com água destilada (2:1 em massa) e deixados em repouso por $24 \mathrm{~h}$ para posterior medição.

Para o número de folhas, diâmetro dos coletos e altura da parte aérea, os dados foram submetidos à análise de variância (ANOVA) e regressão polinomial. Para os teores relativos de clorofila e diâmetro dos capítulos, realizou-se ANOVA e as médias comparadas pelo teste de Tukey $(P \leq 0,05)$. Utilizou-se o programa estatístico Sisvar ${ }^{\circledR} 5.6$ (FERREIRA, 2014).

\section{RESULTADOS E DISCUSSÃO}

Na Tabela 1 observa-se os valores das condutividades elétricas e dos $\mathrm{pH}$ dos substratos ao final do período experimental. Verificou-se que a adição de percolado ocasionou acréscimo na condutividade elétrica dos substratos, sendo ainda mais elevada em substratos irrigados com solução de $\mathrm{NaCl}$ a $60 \mathrm{mM}$. Contudo, as condutividades elétricas mantiveram-se inferiores a 3,53 DS/m, quando o extrato de saturação de um solo é considerado salino (MORAIS et. al., 2011; RICHARDS, 1954;). Esse fato poderia ser atribuído à eficiente drenagem do substrato arenoso. Os pHs mantiveram-se em faixas adequadas para nutrição vegetal, entre 5,85 e 7,11, já que segundo Lepsch (2016), um solo que prejudica o desenvolvimento das plantas possui $\mathrm{pH}$ abaixo de 5,5, podendo causar reduções no crescimento das plantas.

Na Figura 2 é possível observar as curvas de resposta para as variáveis altura da parte aérea (Figuras 2A e 2B), diâmetro do coleto (Figuras 2C e 2D) e número de folhas (Figuras $2 \mathrm{E}$ e 2F) das plântulas de girassol irrigadas com água destilada e solução de $\mathrm{NaCl}$ a $60 \mathrm{mM}$ e suplementadas com percolado de aterro sanitário. De modo geral, verificou-se que as plantas do tratamento que recebeu $80 \mathrm{Kg} \mathrm{N}^{-1}$ se destacaram tanto em condições controle como salinas, seguidas do tratamento de 160 $\mathrm{Kg} \mathrm{N} \mathrm{ha}{ }^{-1}$, que também se apresentou mais elevado em relação ao adubo e areia.

Tabela 1. Condutividades elétricas (CE) e pH dos substratos ao final do período experimental.

\begin{tabular}{lcccccccc}
\hline \multirow{2}{*}{ Variável } & \multicolumn{4}{c}{ Controle } & \multicolumn{3}{c}{ Salino } \\
\cline { 2 - 9 } & Areia & $\begin{array}{c}\text { Fertilizante } \\
\text { Orgânico misto }^{\text {Percolado }}\end{array}$ & $80 \mathrm{Kg} \mathrm{N} \mathrm{ha}^{-1}$ & $\begin{array}{c}\text { Percolado } \\
160 \mathrm{Kg} \mathrm{N} \mathrm{ha}^{-1}\end{array}$ & Areia & $\begin{array}{c}\text { Fertilizante } \\
\text { Orgânico misto }^{\text {Percolado }}\end{array}$ & $\begin{array}{c}\text { Percolado Kg N ha } \\
80\end{array}$ & $\begin{array}{c}\text { Per Kg N ha } \\
160\end{array}$ \\
\hline C.E. (DS/m) & 0,025 & 0,040 & 0,028 & 0,029 & 0,086 & 0,282 & 0,353 & 0,504 \\
\hline pH & 7,11 & 6,61 & 6,41 & 6,13 & 6,37 & 5,83 & 5,95 & 5,85 \\
\hline
\end{tabular}

Segundo Nunes Junior et al. (2016), a aplicação de percolado em etapas pode proporcionar respostas metabólicas nas plantas através do fornecimento de $\mathrm{N}$ e outros macronutrientes. $\mathrm{Na}$ literatura, o nitrogênio é associado facilmente ao crescimento das plantas e sua deficiência causa alterações nas três variáveis analisadas (altura da parte aérea, diâmetro do coleto e número de folhas). Assim, os valores obtidos dos tratamentos que utilizaram percolado como nutriente se sobressaíram dos demais, mostrando-se como uma boa fonte de nutrientes como o nitrogênio.

De modo geral, as curvas de resposta para altura da planta (Figuras 2A e 2B) se comportaram de maneira quadrática. Ao avaliar as plantas em condições controle (Figura 2A), observouse que, no grupo suplementado com percolado a $80 \mathrm{Kg} \mathrm{N} \mathrm{ha}^{-1}$, os resultados foram mais elevados, porém, diferindo dos demais após a terceira coleta de dados. As plantas que menos se desenvolveram foram as do grupo areia, pois esta não recebeu nenhuma suplementação. Não houve drásticas diferenças entre plantas irrigadas com água destilada ou solução salina (Figura 2B), podendo ser explicado pela ocorrência de grande pluviosidade, lixiviando a salinidade aplicada em parte das plantas. 
Figura 2. Altura da parte aérea condições controle (A) e salinas (B), diâmetro do coleto - condições controle (C) e salinas (D), número de folhas - condições controle $(\mathrm{E})$ e salinas $(\mathrm{F})$ de plântulas de girassol em substratos com percolado de aterro sanitário e submetidas à salinidade. Valores médio \pm os erros padrão. *Significativo a 0.01 de probabilidade; **Significativo a 0.05 de probabilidade; ns Não significativo.
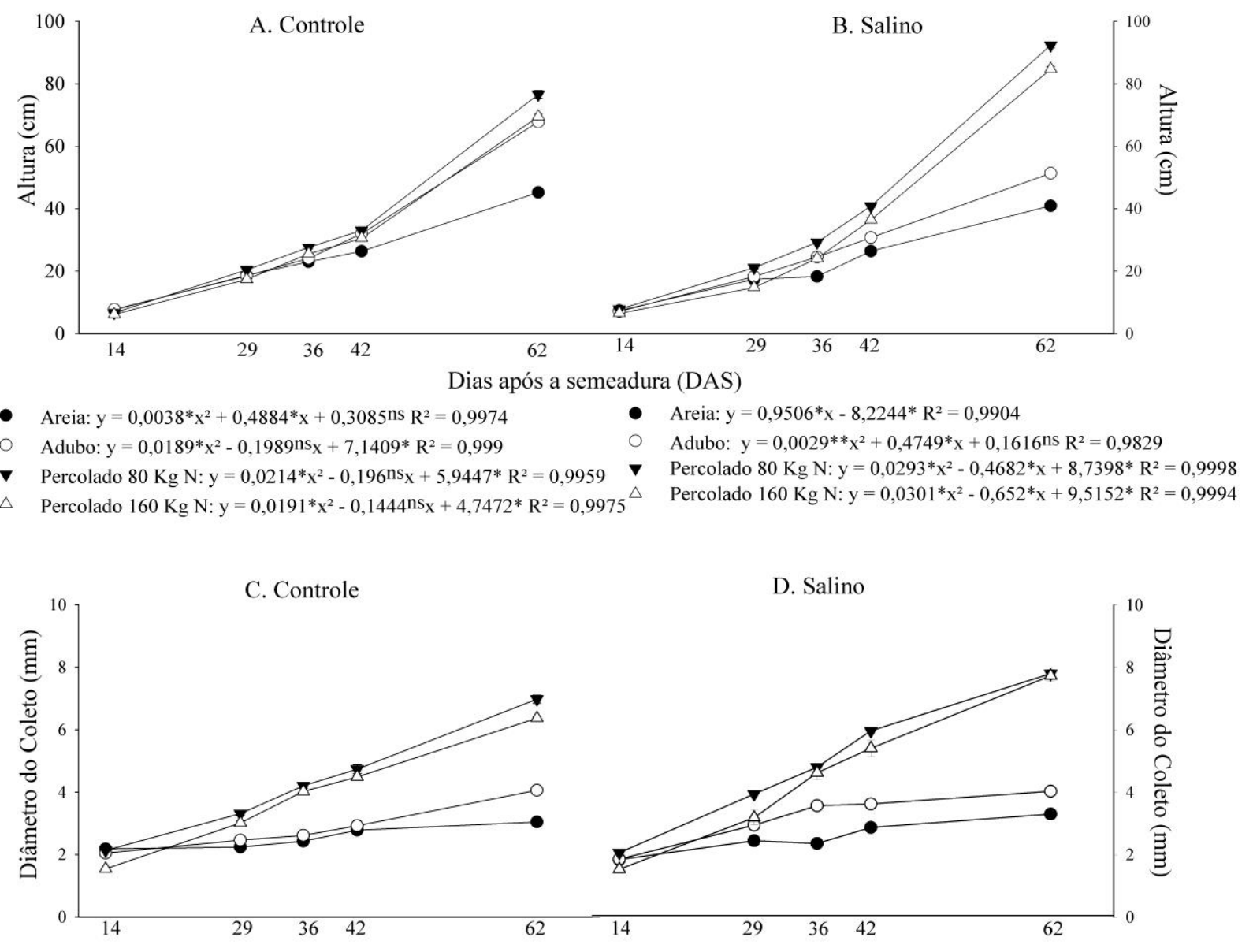

Dias após a semeadura (DAS)

- Areia: $y=-9 \mathrm{E}-05^{* *} \mathrm{x}^{3}+0,0104 * * \mathrm{x}^{2}-0,3383 n \mathrm{~s}_{\mathrm{X}}+5,1666^{*} \mathrm{R}^{2}=0,9614$

Adubo: $\mathrm{y}=0,0008 * \mathrm{x}^{2}-0,0207 \mathrm{~ns}_{\mathrm{x}}+2,2051 * \mathrm{R}^{2}=0,9914$

v Percolado $80 \mathrm{Kg} \mathrm{N}: \mathrm{y}=0,0005 * * \mathrm{x}^{2}+0,0657 * \mathrm{x}+1,1273 * \mathrm{R}^{2}=0,9982$

$\triangle \quad$ Percolado $160 \mathrm{Kg} \mathrm{N}: \mathrm{y}=0,1022 * \mathrm{x}+0,114$ ns $^{2}=0,9915$

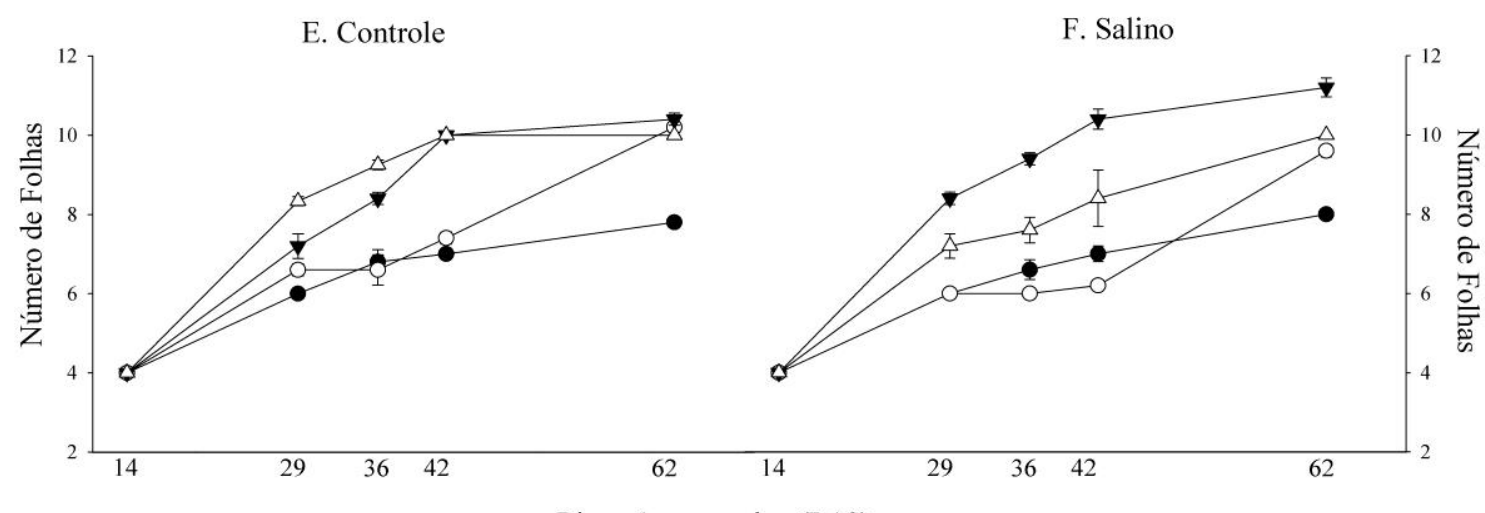

Dias após a semeadura (DAS)

Areia: $y=-0,0014 * x^{2}+0,1795 * x+1,8507 * * R^{2}=0,977$

Adubo: $y=0,1252 * x+2,3011 * R^{2}=0,9775$

- Areia: $y=-0,0013 * * x^{2}+0,183 * x+1,7238 * * \mathrm{R}^{2}=0,9985$

v Percolado $80 \mathrm{Kg} \mathrm{N}: \mathrm{y}=-0,0041 * \mathrm{x}^{2}+0,4513 * \mathrm{x}-1,7153 \mathrm{~ns}^{2}=0,9501$

$\triangle \quad$ Percolado $160 \mathrm{Kg} \mathrm{N}: \mathrm{y}=-0,0051 * \mathrm{x}^{2}+0,5082 * \mathrm{x}-2,098 * \mathrm{R}^{2}=0,9912 \triangle$
- Areia: $\mathrm{y}=0,0311 * \mathrm{x}+1,3925 * \mathrm{R}^{2}=0,9434$

Adubo: $y=-0,001 * x^{2}+0,1192 * x+0,3823 n s R^{2}=0,979$

ק Percolado $80 \mathrm{Kg} \mathrm{N}: \mathrm{y}=0,1204 * \mathrm{x}+0,4166^{\mathrm{ns}} \mathrm{R}^{2}=0,9836$

$\triangle \quad$ Percolado $160 \mathrm{Kg} \mathrm{N}: \mathrm{y}=0,1303 * \mathrm{x}-0,2209 \mathrm{~ns}^{2} \mathrm{R}^{2}=0,9962$

F. Salino

Adubo: $\mathrm{y}=0,0002 * * \mathrm{x} 3-0,0198 * * \mathrm{x}^{2}+0,7161 * * \mathrm{x}-2,6447 \mathrm{~ns} \mathrm{R}^{2}=0,9995$

Percolado $80 \mathrm{Kg} \mathrm{N}: \mathrm{y}=-0,0039 * \mathrm{x}^{2}+0,4468 * x-1,44566^{\mathrm{ns}} \mathrm{R}^{2}=0,9981$

Percolado $160 \mathrm{Kg} \mathrm{N}: \mathrm{y}=-0,0018 * \mathrm{x}^{2}+0,2589 * \mathrm{x}+0,8256 \mathrm{NS} \mathrm{R}^{2}=0,9888$ 
Diferentemente do presente trabalho, Oliveira et al. (2010), quando analisaram diferentes suplementações de nitrogênio atreladas à salinidade, observaram que o crescimento em altura das plantas de girassol foi afetado negativamente pelo aumento da pressão osmótica, o que desencadeia uma plasmólise celular. Ribeiro et al. (2016), também em girassol, ao analisar salinidades da água de irrigação de 0,5 a $4,5 \mathrm{dSm}^{-1}$ com porcentagens crescentes de nitrogênio, concluíram que, após 30 dias da semeadura, surgiram efeitos negativos no crescimento das plantas.

A Figura 2C mostra o diâmetro do coleto de plantas sob condições controle. Observaram-se curvas de resposta cúbica (areia), quadrática (adubo e percolado $80 \mathrm{Kg} \mathrm{N}^{-1}$ ) e linear (percolado $160 \mathrm{Kg} \mathrm{N} \mathrm{ha}^{-1}$ ). No entanto, quando analisadas as plantas sob irrigação salina, foi possível observar que a sua maioria se encaixou no modelo linear crescente, exceto as plantas que foram suplementadas com adubo.

Assim como na altura, as plantas suplementadas com a dose $80 \mathrm{~kg} \mathrm{~N}$ ha $^{-1}$ de percolado obtiveram um maior diâmetro do coleto em relação aos demais tratamentos. Na condição controle, esse resultado chegou a ser $129 \%$ maior do que as plantas cultivadas somente com areia, na última avaliação. Adicionalmente, comparando-se às plantas suplementadas com percolado a $80 \mathrm{~kg} \mathrm{~N}^{-1}$ sob condições salinas àquelas sob condições controle, verificou-se que os valores foram $11,4 \%$ maiores na condição salina.

Por outro lado, Santos Júnior et al. (2014), cultivando plantas de girassol em diferentes concentrações de sal em sistema hidropônico, observaram que houve decréscimo no diâmetro do coleto, sendo acentuado quando a água de irrigação apresentava valores a partir de $6,0 \mathrm{dS} \mathrm{m}^{-1}$.

Ao avaliar diâmetro das plantas de girassol fertirrigadas com porcentagens crescentes de percolado + água de abastecimento, Coelho et al. (2018) constataram que as plantas obtiveram crescimento satisfatório deste parâmetro quando utilizadas baixas porcentagens de percolado (até $60 \%$ percolado $+40 \%$ água de abastecimento).

Para o número de folhas (Figuras $2 \mathrm{E}$ e $2 \mathrm{~F}$ ), as equações ajustaram-se ao modelo quadrático. Adicionalmente, sob condições controle, não houve diferença entre os tratamentos contendo percolado e adubo. Além disso, as médias desses tratamentos foram $31 \%$ (adubo), 33\% (percolado $80 \mathrm{Kg} \mathrm{N}^{-1}$ ) e $28 \%$ (percolado $160 \mathrm{Kg} \mathrm{N} \mathrm{ha}^{-1}$ ) superiores ao de areia. Sob salinidade, os maiores valores foram detectados no tratamento contendo percolado a $80 \mathrm{~kg} \mathrm{~N}^{-1}$. Adicionalmente, os valores não diferiram das plantas irrigadas com água não salina. Nunes Júnior et al. (2016), observaram reduções no número de folhas quando submeteram plantas de girassol ao percolado a $100 \mathrm{Kg}$ $\mathrm{Nha}^{-1}$.

Para os teores relativos de clorofila (Figura 3), verificou-se tanto em condições controle como salinas uma tendência de acréscimo nos valores dos tratamentos contendo percolado. Sob condições controle, a média nas plantas do tratamento com percolado a $80 \mathrm{~kg}$ de $\mathrm{N}$ foi $15 \%$ maior que a do tratamento areia. Sob salinidade, esses valores foram $18 \%$ maiores que o adubo.
Figura 3. Teores relativos de clorofila (índice SPAD) de plântulas de girassol em substratos com percolado de aterro sanitário e submetidas a irrigação com água destilada (A) ou solução de $\mathrm{NaCl}$ a $60 \mathrm{mM}$ (B) aos 42 dias após a semeadura (DAS). Diferentes letras indicam diferenças significativas em relação às diferentes suplementações de $\mathrm{N}$ em cada condição de irrigação (controle ou $\mathrm{NaCl}$ a $60 \mathrm{mM}$ ) de acordo com o teste de Tukey $(p \leq 0,05)$. Valores médios \pm os erros padrão.
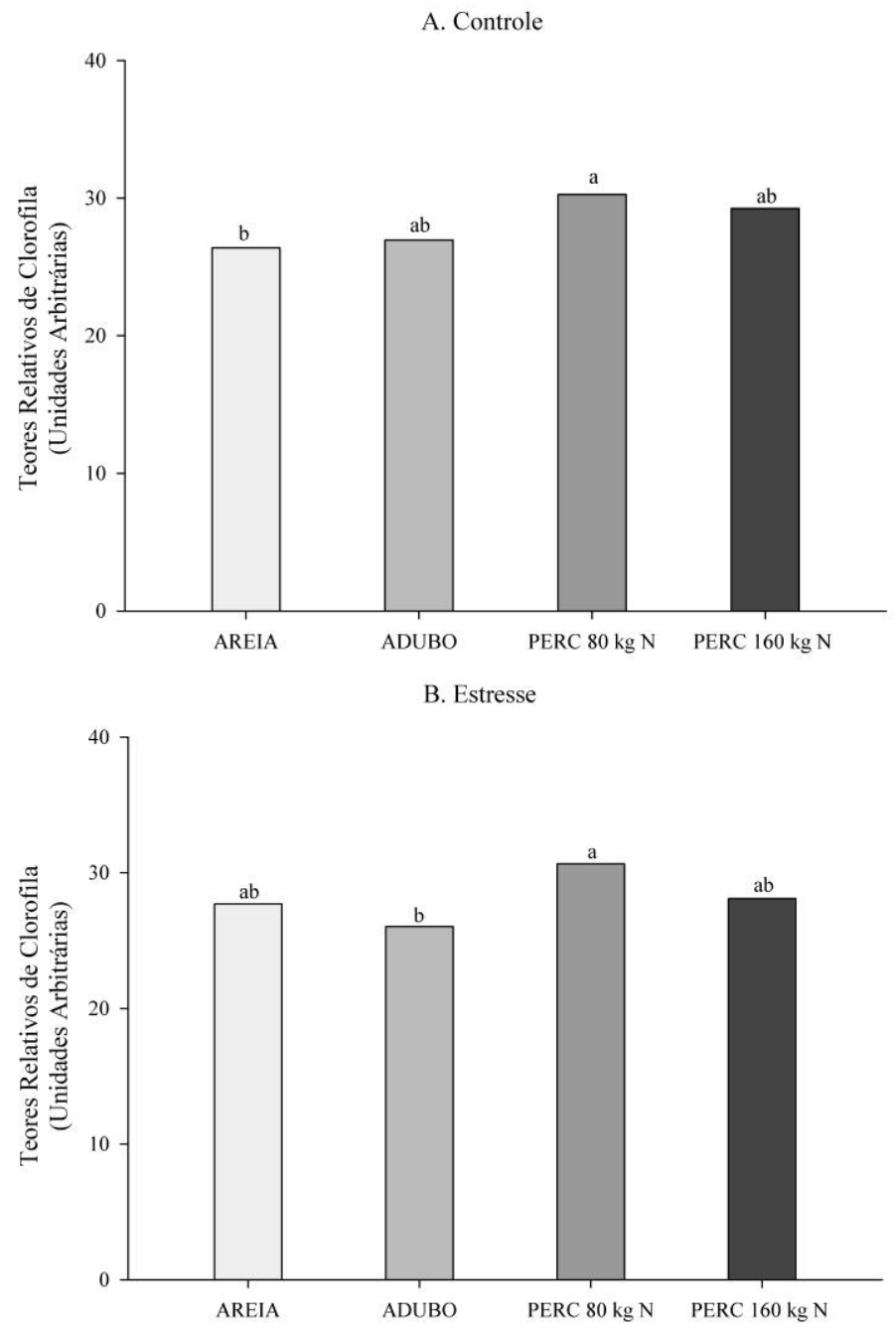

A aplicação de percolado de aterro sanitário ocasionou incremento dos diâmetros dos capítulos (Figura 4), principalmente sob condições salinas não havendo diferença significativa entre os tratamentos a 80 e $160 \mathrm{~kg}$ de N, sendo a média desses tratamentos foram $194 \%$ e $177 \%$ superiores à média do substrato areia.

Ao avaliar diferentes doses de nitrogênio, Guedes Filho et al. (2015), também encontraram maior diâmetro do capítulo de acordo com as doses adotadas e com as diferentes concentrações salinas utilizadas, presumindo que o nitrogênio é responsável por atenuar os efeitos deletérios do sal. 
Figura 4. Diâmetro do capítulo de plantas de girassol em substratos com percolado de aterro sanitário e submetidas a irrigação com água destilada (barras brancas) ou solução de $\mathrm{NaCl}$ a $60 \mathrm{mM}$ (barras cinzas). Conforme o teste de Tukey ( $p \leq$ $0,05)$, as diferentes letras maiúsculas indicam diferenças significativas devido ao tipo de irrigação (controle e salino), enquanto diferentes letras minúsculas diferenças significativas devido aos substratos empregados.

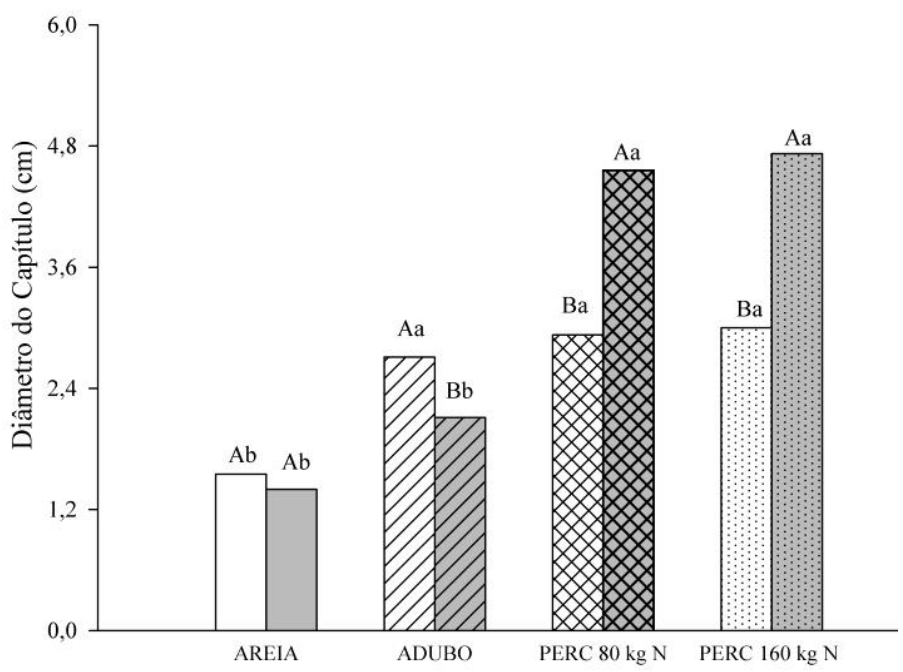

Diante de tais resultados, observou-se que as plantas suplementadas com percolado de aterro sanitário a $80 \mathrm{~kg} \mathrm{~N} \mathrm{ha}^{-1}$ apresentaram os melhores resultados, possibilitando uma maior suplementação nutricional às plantas de girassol e favorecendo o seu crescimento. No entanto, a irrigação com água de moderada concentração salina $(60 \mathrm{mM}$ de $\mathrm{NaCl})$, não ocasionou alterações nas variáveis de crescimento analisadas. Acredita-se que o uso de substrato arenoso e vasos dotados de furos para drenagem, associados ao período chuvoso sejam responsáveis pela ausência de diferenças drásticas entre plantas sob condições controle e salinas.

\section{CONCLUSÕES}

A aplicação de percolado de aterro sanitário na concentração de $80 \mathrm{Kg} \mathrm{N} \mathrm{ha}^{-1}$ promove incrementos em todas as variáveis de crescimento vegetativo e reprodutivos nas plantas de girassol. A irrigação com solução de $\mathrm{NaCl}$ a $60 \mathrm{mM}$ em substratos arenosos não ocasiona efeitos negativos sobre as variáveis de crescimento em girassol.

\section{REFERÊNCIAS}

ASSOCIAÇÃO BRASILEIRA DE NORMAS TÉCNICAS. Rochas e solos. NBR 6502. Rio de Janeiro, 1995.

COELHO, D. D. C. L.; JÚNIOR, A. O. M.; DA SILVA, K. B.; DA SILVA DIAS, N.; BATISTA, R. O. Produção de girassol fertirrigado com percolado de aterro sanitário. Revista Caatinga, v. $31, \quad$ n. 4 , p. 944-953, 2018. 10.1590/198321252018v31n417rc
DE MORAIS, F.A.; GURGEL, M.T.; DE OLIVEIRA, F.H.T.; MOTA, A. F. Influência da irrigação com água salina na cultura do girassol. Revista Ciência Agronômica, v. 42, n. 2, p. 327336, 2011.

DA SILVA, T. G. F.; ZOLNIER, S.; GROSSI, J. A. S.; BARBOSA, J. G.; MOURA, C. R. W.; Muniz, M. A. Crescimento do girassol ornamental cultivado em ambiente protegido sob diferentes níveis de condutividade elétrica de fertirrigação. Ceres, v. 56, n. 5, 2015.

FERREIRA, D. F. Sisvar: a Guide for its Bootstrap procedures in multiple comparisons. Ciência e agrotecnologia, v. 38, n. 2, p. 109-112, 2014.

GAZZOLA, A.; FERREIRA JUNIOR, C. T. G.; CUNHA, D. A., BORTOLINI, E.; PAIAO, G. D.; PRIMIANO, I. V.; PESTANA, J.; D'ANDRÉA, M.S.C.; OLIVEIRA, M. S. A cultura do girassol. Piracicaba: ESALQ, v. 69, 2012.

GUEDES FILHO, D. H.; DOS SANTOS, J. B.; GHEYI, H. R.; CAVALCANTE, L. F.; SANTOS JUNIOR, J. A. Componentes de produção e rendimento do girassol sob irrigação com águas salinas e adubação nitrogenada. IRRIGA, v. 20, n. 3, p. 514, 2015. 10.15809/irriga.2015v20n3p514

LEPSCH, I. F. Formação e conservação dos solos. Oficina de textos, 2016.

NUNES JUNIOR, F. H.; GONDIM, F. A.; PEREIRA, M. de S.; BRAGA, B. B.; PONTES FILHO, R. A.; BARBOSA, F. E. L. Sanitary landfill leachate as a source of nutrients on the initial growth of sunflower plants. Revista Brasileira de Engenharia Agrícola e Ambiental, v.20, p. 746-750, 2016.

OLIVEIRA, F. D. A. D.; DE OLIVEIRA, F. R.; CAMPOS, M. D. S.; DE OLIVEIRA, M. K.; MEDEIROS, J. F. D.; SILVA, O. M. D. P. Interação entre salinidade e fontes de nitrogênio no desenvolvimento inicial da cultura do girassol. Revista Brasileira de Ciências Agrárias, v. 5, n. 4, 2010. 10.5239/agraria.v5i4.806

RIBEIRO, P. H. P.; GHEYI, H. R.; UYEDA, C. A.; TEIXEIRA, M. B.; SOARES, F. A. L.; DIAS, N. D. S. Taxa de crescimento e produção de girassol irrigado com água salina sob doses de nitrogênio. IRRIGA, v. 1, n. 1, p. 233, 2016. 10.15809/irriga.2016v1n1p233-247

RICHARDS, L. A. Diagnosis and improvement of saline and alkali soils. United States Salinity Laboratory Staff. United States Department of Agriculture Handbook $n^{\circ}$ 60. USA. 1954.

SANTOS JÚNIOR, J. A.; GHEYI, H. R.; DIAS, N. D. S; ARAUJO, D. L.; GUEDES FILHO, D. H. Substratos e diferentes concentrações da solução nutritiva preparada em água residuária no crescimento do girassol. Revista Ciência Agronômica, v. 45, n. 4, 2014. 10.1590/S1806$\underline{66902014000400007}$ 
SANTOS JÚNIOR, J. A.; GHEYI, H. R.; GUEDES FILHO, D. H.; DIAS, N. S.; SOARES, F. A. L. Cultivo de girassol em sistema hidropônico sob diferentes níveis de salinidade. Revista Ciência Agronômica, v. 42, n. 4, p. 842-849, 2011. $\underline{10.1590 / \mathrm{S} 1806-66902011000400004}$

SANZONOWICZ, C.; AMABILE, R. F. Adubação nitrogenada do girassol, no período chuvoso e na safrinha na região do cerrado. Embrapa Cerrados-Recomendação Técnica (INFOTECA-E), 2001.

SILVA, R. C. B.; SANTANA, G. S.; LEITE, R. L.; BORGES NETO, M. R.; COELHO, F. J. S.; MONTEIRO, G. S. Emergência de sementes de girassol (Helianthus annuus) sob estresse salino irrigado por bombeamento fotovoltaico. Revista Semiárido De Visu, v. 5, n. 2, p. 80-87, 2017.

SILVA, T. T. S; LOPES, R. M. B. P.; GUIMARÃES, J. P.; LIMA, V. L. A.; FARIAS, M. S. S. Efeito da adubação orgânica sobre a matéria seca do girassol irrigado com água residuária. Revista Verde de Agroecologia e Desenvolvimento Sustentável, 2016. 10.18378/rvads.v11i3.3979

SOARES, L. A. A.; DE LIMA, G. S.; CHAVES, L. H.; XAVIER, D. A.; FERNANDES, P. D.; GHEYI, H. R. Fitomassa e produção do girassol cultivado sob diferentes níveis de reposição hídrica e adubação potássica. Revista Brasileira de Engenharia Agrícola e Ambiental, v. 19, n. 4, p. 336-342, 2015. $\underline{10.1590 / 1807-1929 / \text { agriambi.v19n4p336-342 }}$ 